\begin{tabular}{l} 
Year:4, Volume:4, Number:7 / 2020 \\
\hline $\begin{array}{l}\text { The } \\
\text { Sociarnal of } \\
\text { Science }\end{array}$
\end{tabular}

DOI Number: 10.30520/tjsosci.679802

\title{
TOWARDS A BETTER COST AND QUALITY STRUCTURE THROUGH ORGANISATIONAL DEVELOPMENT INTERVENTIONS: A CASE STUDY
}

Dr. Meltem YAVUZ ${ }^{1}$

\begin{abstract}
In order to overcome the challenges of dynamic business environments where fierce competition occurs, and to address the internal firm-level requirements (i.e. effectiveness and efficiency in operations and processes), firms need to change, thus they engage in Organisational Development (OD) interventions. This paper aims to explore the efforts of a family-owned carpet company to change its cost and quality structure through three OD interventions: (1) adapting a new wage and reward system, (2) establishing new manufacturing hubs for the weavers outside of their homes, (3) designing a training programme for the weavers. Findings of the case study bring a reasonable solution to the production-related problem of the SME.
\end{abstract}

Keywords: case study, family-owned companies, occupational psychology, organisational development, SMEs

\section{INTRODUCTION}

Organisational Development (OD) refers to "any practice that serves to deliberately improve problem solving and renewal processes in organisations" (Romme, 2011, p. 9). Similarly, Anderson (2017) defines OD as "the process of increasing organisational effectiveness and facilitating personal and organisational change through the use of interventions driven by social and behavioural science knowledge" (p. 3). Therefore, OD is commonly considered in the organisation literature as "a prominent system-wide approach to planned organisational change based on behavioural science" (Kuna \& Nadiv, 2018, p. 848) and it aims to "facilitate organisational learning" (Burnes \& Cooke, 2012; Lien, Hung, \& McLean, 2007) and to "improve the way organisations work" (Bradford \& Burke, 2005, Sminia \& Van Nistelrooij, 2006).

As a continuous process, OD can be conducted by a single intervention or a series of interventions over time at different levels such as individual, team, organisational or even multiple organisational (large-scale) levels (Church, Shull, \& Burke, 2018; Cummings \& Worley, 2014). The classification of interventions is not limited to level basis. A number of intervention categories reflecting the nature and content of the actions, such as the interventions that are related to human resource practices, re-structuring/re-engineering, technology and strategy are frequently mentioned in the literature (Burke, 2018; Foss, 2003;

\footnotetext{
${ }^{1}$ Independent Researcher, Mind Crafting Academy, meltem@mindcraftingacademy.com
} 
Roberts et al., 2017; van Aken, 2007). Furthermore, Liu (2011) categorises the types of interventions as primary interventions which aim to treat and rehabilitate the main sources of problems and secondary interventions that deal with symptoms of the main problem(s). Therefore, understanding and defining the root causes of a problem and its symptoms thoroughly is critically important for an occupational psychologist to select and implement the most suitable intervention type. The intervention method selected must be consistent with the strategic goals and should align with the objectives that the organisation desires to reach. This study explores the actions of a large family firm to become a more efficient organisation through a number of OD interventions. As a result of a disconfirmation faced by the firm in relation to productivity, cost effectiveness, and future positioning along with competitiveness in the market, the firm believed that it was experiencing challenges that were significant enough to warrant interventions (Busco, Riccaboni, \& Scapens, 2006).

Hence, an OD plan which targets areas such as efficiency and comprises several interventions was introduced in 2015. The OD interventions implemented can be counted as a large-scale plan since it is "characterised by facilitative methods that support bringing large groups of people together - greater than eight - to address and act on issues, challenges, and opportunities that impact them" (Gilpin-Jackson, 2017, p. 420).

\section{IDENTIFICATION OF THE PROBLEM AND INTERVENTION NEEDS}

The development of the small business sector is crucial for economic growth since small to medium enterprises (SMEs) are an important source of innovation, value adding manufacturing, and job creation (Leonidou, Christodoulides, \& Thwaites, 2016). Therefore, studying SME performance is valuable and necessary. This paper aims to explain a production-related problem faced by a family-owned hand-made carpet manufacturing firm in Turkey and a number of interventions used to bring a reasonable solution to the problem. The main problem defined in the firm was high-cost manufacturing resulting from high defective good rates and poor weaving skills of the employees. Besides, the total amount of production was below than the expectations of the firm's management. This situation did not only decrease the profitability of the firm but it also affected its market competitiveness.

Therefore, the firm decided to prepare a series of planned interventions which comprises: a new wage and reward system that promotes productivity of the employees (carpet weaver girls), a new manufacturing method (production in smaller manufacturing units under the control of a skilled foreman) that may decrease the defective good rates, and a training programme to improve the technical skills of the carpet weaver girls. All interventions would contribute to changing the cost structure of the firm towards a more efficient manufacturing firm.

\subsection{Context and Background of the Firm}

Hand-made carpet manufacturing is quite widespread in Turkey and carpet production is done in the regions of Turkey where low-cost labour can be found (generally in the Mid- and East- 
Anatolian and Aegean regions). "Silk Way" hand-made wool and silk carpet manufacturing company was established by two brothers in 1968 in an Anatolian city called Kayseri. In the early years of the business, they collected the carpets from the villages and sold them in a small shop which has been inherited by their fathers. Five years later they owned their looms and started to manufacturing carpets rather than buying from the villagers. The business achieved a successful growth and the younger brother moved to Grand Bazaar in Istanbul to exploit potential growth opportunities. With the EU Customs Union Agreement in 1996, the trade barriers in Turkey were removed and the company started to import raw material from other countries such as silk from China and Turkic Republics, wool from New Zealand and artificial silk from Austria. In 2018, the company had 60 white-collar employees in two offices and nearly 200 carpet weaver girls in the villages.

The hand-made carpet production which includes difficult and monotonous job processes is generally conducted by teenager girls in the villages. While the villager girls weave the carpets, they look at a loom which stands to a wall during the whole day. Besides, their families are generally religious and do not let them go and work outside, thus they do all job in their homes and cannot socialise. The manufacturing is not machine-made and it is open to labour-related mistakes which might result in high rates of defective goods. The job is also painful because thin and sharp silk ropes can cut fingers of the weaver or the wool may create allergic reactions on her skin. Moreover, because of the market conditions, they are offered below average wages. The manufacturing is labour intensive since the labour cost accounts for $75 \%$ whereas the raw material cost accounts for $25 \%$ in the total cost of the good. Therefore, the job skills, and the weaving style and performance of the weavers determine the quality of the product and the defective rate of the output.

\subsection{Identification of the Intervention Needs}

In 2018, top managers of the company noticed a significant $15 \%$ increase in the cost of goods sold item of the balance sheet compared with the last three years' figures. The rate was increasing every year with a rate of nearly $5 \%$. In parallel, the defective good rate of the company was increasing $1.2 \%$ yearly which reached to an overall $8 \%$. In order to understand the nature of the problem, an organisational assessment (Burke \& Litwin, 1992; Stone, 2015) based on the data collected by company documents (financial reports, budgets etc.), observations (customer reactions to the goods), and questionnaires (asking the carpet weavers about their working conditions) was conducted. Although it is a good idea to gather information on the way of identifying the root causes of the main problem from multiple sources (Stone, Brown, Smith, \& Jacobs, 2018) to design suitable interventions, there might be a need to ask more detailed questions to the employees through a number of interviews (i.e. how do they feel while weaving carpets, their perceived weaknesses in the manufacturing process, and what kind of training do they think worth getting etc.) by granting permission from their families. Some psychological instruments (i.e. well-being, job satisfaction etc.) could also be used to collect data. Furthermore, observing them while they weave carpets might provide some job-related technical findings on why, where and how they make mistakes which result in defective output. According to Nielsen and Randall (2013), the 
process of identifying intervention needs should "include a close examination of the psychological and organisational mechanisms that hinder and facilitate desired intervention outcomes" (p. 1). From this point of view, only a few things were asked to the weavers to diagnose the problem, thus it seems that psychological factors were a bit omitted in identifying intervention needs of the organisation and a rather mechanistic investigation was done for this purpose.

One clue to understand the increase in the defective good rate emerged from the HR department: high turnover rate among the weavers. Resulting from the poor and monotonous working conditions along with low salaries offered, most of the girls became unsatisfied and unhappy. This situation did not only influence their job performance, but it also led to a high employee turnover rate. High employee turnover is a serious concern in this business because each weaver has a different weaving style and if a weaver leaves the job and the uncompleted carpet remains on the loom, another weaver continues to complete the carpet with her own weaving style which increases the risk of having a defective good. Therefore, a high turnover rate directly effects the defective good rate negatively since a carpet must be weaved completely by the same employee.

Finally, since nearly all processes of carpet production is realised in the houses of weaver girls, it is not possible for another expert to control the manufacturing and intervene for a correction or a remedy where required. So, the firm provides raw material to the weavers and waits to get whatever is produced in the houses. In this context, an intervention that enables the weavers work in small manufacturing units close to their homes under responsibility of an expert and experienced foreman can be designed. Thus, the production process can be controlled completely and the defective good rate can be lowered through pro-active or corrective actions of the foreman.

Carpet manufacturing has unique business and working conditions and it requires contextdependent interventions for OD. Therefore, in line with Nielsen and Randall (2012) who suggest that "intervention activities [should be] tailored to the problem as it is manifested itself in the specific organisational context" (p. 4), Silk Way hand-made carpet manufacturing company conducted three interventions: (1) adapting a new wage and reward system, (2) establishing new manufacturing hubs for the weavers outside of their homes, (3) designing a training programme for the weavers.

\section{Organisational Development Interventions}

\section{Intervention 1: A new wage and reward system}

Consistent with the efforts to increase productivity (or job performance) of the employees and decrease the defective good rate leading to lower cost manufacturing, a new wage and reward system was introduced. Before this intervention, the wages of the weavers were merely calculated based on the quantity of piece produced with no other criteria for wage calculation. A number of theorists (i.e. Lemieux, MacLeod, \& Parent, 2009; Piketty \& Saez, 2003) suggest that wages should be adjusted according to the productivity based criteria because 
"fixed wage system may discourage employees to perform better" (Lemieux et al., 2009, p. 7).

Therefore, a new performance-related pay (PRP) scheme to stimulate employees' job performance and promote product quality was announced. Shelley (1999) describes PRP as "the explicit link of financial reward to individual, group or company performance and part of a re-orientation of pay and reward systems away from traditional methods of job evaluation and time-based pay, often carried out on a collective basis, to a more individualised approach which recognises employee contributions" (p. 443). The rationale behind the application of PRP which has the roots with the expectancy and the reinforcement theories is that the weavers show additional effort to the extent that they "expect valuable outcomes from their actions" (Perry et al., 2012, p. 57) and perceive rewards worth working for. Empirical evidence (i.e. Atkinson et al., 2009; Dahlström \& Lapuente, 2009; Malik, Butt, \& Choi, 2015) indicates that PRP promotes job performance and motivation. In line with these empirical findings and suggestions, the firm adapted a new wage system that offers incremental changes on the wage of a weaver if she can produce more than a certain amount of good. Besides, the system encouraged the weaver by bonus premiums if she achieved a defective good rate, $5 \%$ or below in her total yearly production. While amount of the production increased $15 \%$, the overall defective good rate dropped down from $8 \%$ to $7 \%$ over a year. Therefore, the intervention yielded a quick outcome but some time is needed for more satisfactory results.

Intervention 2: New manufacturing units (hubs)

Researchers have linked working conditions and organisational outcomes (Ketchen et al., 1997; Ostroff, Kinicki, \& Tamkins, 2003; Sell \& Cleal, 2011; Smith, Oczkowski, \& Smith, 2011). While a good quality of work environment encourages employees to perform better through increasing several organisational outcomes such as job satisfaction, well-being, commitment, reduced stress, and citizenship (Berg, Kalleberg, \& Appelbaum, 2003; Gajendran \& Harrison, 2007; Spivack \& Milosevic, 2018; Uhl-Bien \& Arena, 2018), in contrast, poor working environment can result in organisational inefficiencies (demotivation, intention to leave and turnover etc.). In our specific context, all production has been made in the weavers' homes where co-worker relations lack and dull and depressive factors exist. Moreover, the weaver was alone and there was no better skilled and/or expert person to intervene the production process (i.e. a foreman) on the way of providing advices to the weaver or taking actions which lead to decreased defective good rate.

Therefore, the firm clustered the weaver girls based on some criteria (geographical location had the priority but similarity in skills and productivity were considered) established a number of small manufacturing units (as manufacturing hubs) which were planned to be in optimum distances to the houses of weavers. These units did not only provide much better working conditions and a pleasant atmosphere to socialise with each other, they also enabled the weavers to get help from the foremen where required. This OD intervention promoted "employee involvement, participation and identification which can be very helpful to the organisations undergoing change processes" (Bicknell, 2016). Therefore, "the potential [of the OD intervention] to have both direct and indirect effects on the workplace" (Lerner, 2015, 
p. 2) was utilised in parallel with the Randall, Cox, and Griffiths' (2007) explanation highlighting that "OD interventions often have wide-reaching effects; a worker whose job has been effectively restructured will not only be able to do his or her own job better, but will also be more able to interact with his or her coworkers in a more positive and helpful manner" (Lerner, 2015, p. 2). Additionally, the foremen had some regular checks in different stages of the production process, so they could intervene the process to ameliorate problematic issues leading to high defective rate.

Any OD intervention should be tailored according to the needs of key stakeholders to address the problems defined and "the correct tailoring of an intervention to the needs of stakeholders requires a thorough risk assessment" (Nielsen \& Randall, 2012, p. 4). Thus, it is important to understand the reactions of the families of the weavers because if the families do not allow the girls to work outside home, the firm may lose some of its highly skilled employees. In line with Nielsen and Randall's (2012) suggestions, the firm organised some seminars and "happy hour" types of meetings to inform the families of the weavers to explain the reason of changing the system (i.e. the benefits of the system to increase happiness, well-being, performance and income of the girls). Most of the families were convinced and the system was adapted. Some positive outcomes were observed but the pure contribution of this intervention cannot be assessed at this stage.

\section{Intervention 3: The training programme}

A training programme was designed to improve the technical weaving skills of the employees based on the data gathered from the questionnaire and comments of the skilled foremen. Therefore, training needs of the weavers were determined by only limited data. Training needs analysis "examines where and what training is required in an organisation" (Bicknell, 2016) and the analysis should collect data from multiple sources for a suitable design and successful conduct. The design of training related intervention has completely focused on carpet weaving skills, however, it acould include some psychology related content (i.e. selfmotivation, self-efficacy, stress and conflict management). From this point of view, the intervention might be considered as a rather mechanistic design which lacks human related (organic) components. The actual results of the intervention is not measured yet since the results of training can be transferred into performance in the long run (Kirkpatrick, 1994; Lim \& Morris, 2006).

\section{CONCLUSION}

This paper aimed to explore the efforts of a family-owned SME to change its cost and quality structure via three OD interventions. The OD interventions which have dynamic and iterative processes started in December 2018, thus it is still an early stage to assess their expected outcomes but some satisfactory results have already been observed even if not completely. Against the motivation, willingness and goodwill of top management on the way of implementing successful OD interventions, particularly, one point can be criticised. At the designing stage of the implementations, some human-related elements (i.e. psychological factors in designing training intervention) seemed to be ignored. Considering the high risk of 
failure of the OD interventions which disregard participative and consultative elements in the design and implementation stages, the owners or the managers of firms should consider the importance of external occupational psychologists (Bartlett \& Francis-Smythe, 2016; Hodgkinson, 2011). In particular, occupational psychologists may play crucial roles at the preceding steps of the learning, training and development interventions which require a thorough analysis of "the responsibilities, tasks, working conditions, organisational position and knowledge, skills and abilities relevant to a given role" (Koczwara \& Ashworth, 2013, p. 300). Finally, one thing should be noted that each intervention designed should include context-specific elements and no standard type of design should be used as an all-fitssolution.

\section{References}

Antal, A. B., Debucquet, G., \& Frémeaux, S. (2018). Meaningful work and artistic interventions in organizations: Conceptual development and empirical exploration. Journal of Business Research, 85, 375-385.

Atkinson, A., Burgess, S., Croxson, B., Gregg, P., Propper, C., Slater, H., \& Wilson, D. (2009). Evaluating the impact of performance-related pay for teachers in England. Labour Economics, 16(3), 251-261.

Bartlett, D., \& Francis-Smythe, J. (2016). Bridging the divide in work and organizational psychology: evidence from practice. European Journal of Work and Organizational Psychology, 25(5), 615-630.

Berg, P., Kalleberg, A. L., \& Appelbaum, E. (2003). Balancing work and family: The role of high-commitment environments. Industrial Relations: A Journal of Economy and Society, 42(2), 168-188.

Bicknell, A. (2016). Module Notes for Unit 2: Models and Methods of Organisational and Individual Change and Development, Personal Collection of A. Bicknell, University of Leicester, Leicester, UK.

Busco, C., Riccaboni, A., \& Scapens, R. W. (2006). Trust for accounting and accounting for trust. Management Accounting Research, 17(1), 11-41.

Burke, W. W. (2017). Organization change: Theory and practice. Oaks: Sage Publications.

Burke, W. W., \& Litwin, G. H. (1992). A causal model of organizational performance and change. Journal of Management, 18(3), 523-545.

Burnes, B., \& Cooke, B. (2012). The past, present and future of organization development: Taking the long view. Human Relations, 65(11), 1395-1429.

Church, A. H., Shull, A. C., \& Burke, W. W. (2018). A look in the mirror: Current research findings on the values and practice of OD. In Enacting Values-Based Change (pp. 21-42). Palgrave Macmillan, Cham.

Cummings, T. G., \& Worley, C. G. (2014). Organization development and change. Stamford, CT: Cengage learning. 
Dahlström, C., \& Lapuente, V. (2009). Explaining cross-country differences in performancerelated pay in the public sector. Journal of Public Administration Research and Theory, 20(3), 577-600.

Foss, N. J. (2003). Selective intervention and internal hybrids: Interpreting and learning from the rise and decline of the Oticon spaghetti organization. Organization Science, 14(3), 331349.

Gajendran, R. S., \& Harrison, D. A. (2007). The good, the bad, and the unknown about telecommuting: Meta-analysis of psychological mediators and individual consequences. Journal of Applied Psychology, 92(6), 1524-1541.

Gilpin-Jackson, Y. (2017). Participant experiences of transformational change in large-scale organization development interventions (LODIs). Leadership \& Organization Development Journal, 38(3), 419-432.

Hodgkinson, G. P. (2011). Why evidence-based practice in I-O psychology is not there yet: Going beyond systematic reviews. Industrial and Organizational Psychology, 4(1), 49-53.

Ketchen, D., Combs, J., Russell, C., Shook, C., Dean, M., Runge, J., et al. (1997). Organizational configurations and performance: A meta analysis. Academy of Management Journal, 40(1), 223-240.

Kirkpatrick, D. L. (1994) Evaluating Training Programs: The Four Levels, San Francisco, CA: Berrett- Koehler.

Koczwara, A., \& Ashworth, V. (2013). Selection and assessment. Work and occupational psychology: Integrating theory and practice, 295-342.

Kuna, S., \& Nadiv, R. (2018). Divided we stand? Occupational boundary work among human resource managers and external organization development practitioners. Employee Relations.

Lemieux, T., MacLeod, W. B., \& Parent, D. (2009). Performance pay and wage inequality. The Quarterly Journal of Economics, 124(1), 1-49.

Leonidou, L. C., Christodoulides, P., \& Thwaites, D. (2016). External Determinants and Financial Outcomes of an Eco-friendly Orientation in Smaller Manufacturing Firms. Journal of Small Business Management, 54(1), 5-25.

Lerner, J. M. (2015). The impact of organizational development interventions on stress and engagement. Unpublished Doctoral dissertation, Capella University.

Lien, B. Y. H., Hung, R. Y., \& McLean, G. N. (2007). Organizational learning as an organization development intervention in six high-technology firms in Taiwan: An exploratory case study. Human Resource Development Quarterly, 18(2), 211-228.

Lim, D. H., \& Morris, M. L. (2006). Influence of trainee characteristics, instructional satisfaction, and organizational climate on perceived learning and training transfer. Human Resource Development Quarterly, 17(1), 85-115. 
Liu, W. K. (2011). Employee assistance programmes in multinational companies: An analysis with proposals. International Journal of Management, 28(3), 740-750.

Malik, M. A. R., Butt, A. N., \& Choi, J. N. (2015). Rewards and employee creative performance: Moderating effects of creative self-efficacy, reward importance, and locus of control. Journal of Organizational Behavior, 36(1), 59-74.

Nielsen, K., \& Randall, R. (2013). Opening the black box: Presenting a model for evaluating organizational-level interventions. European Journal of Work and Organizational Psychology, 22(5), 601-617.

Ostroff, C., Kinicki, A. J., \& Tamkins, M. M. (2003). Organizational culture and climate. In W. C. Borman, D. R. Ilgen, \& R. J. Klimoski (Eds.), Comprehensive handbook of psychology (pp. 565-593). New York: Wiley.

Perry, J. L., Engbers, T. A., Commentators, S. Y. J., Houston, D. J., Pandey, S. K., \& Risher, H. (2012). Back to the future? Performance-related pay, empirical research, and the perils of persistence. In Debating Public Administration, Routledge, pp. 53-92.

Piketty, T., \& Saez, E. (2003). Income inequality in the United States, 1913-1998. The Quarterly Journal of Economics, 118(1), 1-41.

Randall, R., Cox, T., \& Griffiths, A. (2007). Participants' accounts of a stress management intervention. Human Relations, 60(8), 1181-1209.

Roberts, B. W., Luo, J., Briley, D. A., Chow, P. I., Su, R., \& Hill, P. L. (2017). A systematic review of personality trait change through intervention. Psychological Bulletin, 143(2), 1-25.

Romme, A. G. L. (2011). Organizational development interventions: An artifaction perspective. The Journal of Applied Behavioral Science, 47(1), 8-32.

Sell, L. and Cleal, B. (2011), 'Job satisfaction, work environment, and rewards: Motivational theory revisited', Labour, 52, 1-23.

Shelley, S. (1999). Diversity of appraisal and performance-related pay practices in higher education. Personnel Review, 28(5/6), 439-454.

Smith, A., Oczkowski, E., and Smith, C. S. (2011), 'To have and to hold: modelling the drivers of employee turnover and skill retention in Australian organisations', The International Journal of Human Resource Management, 22, 395-416.

Sminia, H., \& Van Nistelrooij, A. (2006). Strategic management and organization development: Planned change in a public sector organization. Journal of Change Management, 6(1), 99-113.

Spivack, A. J., \& Milosevic, I. (2018). Perceived Location Autonomy and Work Environment Choice: The Mediating Influence of Intrinsic Motivation. The Journal of Applied Behavioral Science, 54(3) 325-348.

Stone, K. B. (2015). Burke-Litwin Organizational Assessment Survey: Reliability and Validity. Organization Development Journal, 33(2), 33-50. 


TJSS|

Stone, K. B., Brown, L., \& Smith, S. L. (2018). Organizational Assessment: An integrated approach to diagnosis and interventions. Organization Development Journal, Spring Issue, 67-95.

Uhl-Bien, M., \& Arena, M. (2018). Leadership for organizational adaptability: A theoretical synthesis and integrative framework. The Leadership Quarterly, 29(1), 89-104.

Van Aken, J. E. (2007). Design science and organization development interventions: Aligning business and humanistic values. The Journal of Applied Behavioral Science, 43(1), 67-88. 